\title{
Common elements and features of a mobile-based self-management system for people living with HIV
}

\author{
Esmaeil Mehraeen ${ }^{1}$, Reza Safdari², SeyedAhmad SeyedAlinaghi ${ }^{3}$, Niloofar Mohammadzadeh ${ }^{4}$, Minoo Mohraz $^{5}$
}

${ }^{1} \mathrm{Ph} . \mathrm{D}$. Candidate of Health Information Management, School of Allied Medical Sciences, Tehran University of Medical Sciences, Tehran, Iran

${ }^{2}$ Ph.D. of Health Information Management, Professor, Department of Health Information Management, Tehran University of Medical Sciences, Tehran, Iran

${ }^{3}$ Assistant Professor, Iranian Research Center for HIV/AIDS, Iranian Institute for Reduction of High Risk Behaviors, Tehran University of Medical Sciences, Tehran, Iran

${ }^{4} \mathrm{Ph} . \mathrm{D}$. of Health Information Management, Assistant Professor, Department of Health Information Management, Tehran University of Medical Sciences, Tehran, Iran

${ }^{5}$ Professor, Iranian Research Center for HIV/AIDS, Iranian Institute for Reduction of High Risk Behaviors, Tehran University of Medical Sciences, Tehran, Iran

\section{Type of article: Original}

\begin{abstract}
Background: In recent years, mobile-based applications have become important technologies to the delivery of healthcare around the world. Mobile-based self-management systems with standard features for providing, evaluating, and improving HIV care are significantly required in developing countries.

Objective: To determine the common elements of a mobile-based self-management system for people living with HIV (PLWH).

Methods: This cross-sectional study was done in two main phases in 2017. In the first phase, a review was conducted in relevant databases such as; PubMed, Scopus, Up To Date, and Web of Science. The keywords used to search for resources were as follows; Self-care, Self-management, Data elements, Minimum data set, Mobile application, Mobile health, and HIV/AIDS. In the second phase, the infectious diseases specialists and health information managers affiliated with Tehran University of Medical Sciences were consulted to score identified elements by a questionnaire. Frequency and mean of collected data were calculated using SPSS software (version 19).

Results: By full-text reviewing of 9 related articles, the identified elements were justified in 3 main categories and 37 subcategories including: clinical data elements (17), technical capabilities (12) and demographic data elements (8). According to the findings, among the clinical category, 11 data elements were selected by the statistical population. Among the identified technical capabilities, 11 features were selected. Moreover, 6 data elements were selected as the demographic category.

Conclusion: We obtained data elements and technical capabilities of a mobile-based self-management system for people living with HIV. Using these elements and features, designing of self-management system architecture will be possible. Self-management skills of PLWH and their communication with healthcare providers will improve by using this system.
\end{abstract}

Keywords: Data element, Technical, Self-management, HIV, AIDS

\section{Introduction}

According to the Joint United Nations Programme on HIV/AIDS (UNAIDS), about 40 years after the onset of this chronic condition, more than 30 million people live with this condition and 10 million are at Acquired Immunodeficiency Syndrome (AIDS) phase and must receive treatment (1). AIDS is a spectrum of conditions

\section{Corresponding author:}

Professor Dr. Reza Safdari. Tel: +98.9121494760, Fax: +98-21-88982905, Email: rsafdari@tums.ac.ir

Received: August 29, 2017, Accepted: January 10, 2018, Published: April 2018

iThenticate screening: December 28, 2017, English editing: April 12, 2018, Quality control: April 14, 2018

This article has been reviewed / commented by five experts

(C) 2018 The Authors. This is an open access article under the terms of the Creative Commons Attribution-NonCommercialNoDerivs License, which permits use and distribution in any medium, provided the original work is properly cited, the use is non-commercial and no modifications or adaptations are made. 
caused by infection with the HIV. Following initial infection, a person may not notice any symptoms or may experience a brief period of influenza-like illness (2). Typically, this is followed by a prolonged period with no symptoms. As the infection progresses, it interferes more with the immune system, increasing the risk of common infections like tuberculosis, as well as other opportunistic infections $(3,4)$. Due to the chronicity of the disease and the increased number of people living with HIV (PLWH), these people need to be aware of their illness, not only in terms of their life expectancy but also in terms of the quality of life (5). Enabling these people to have management of their condition has been enumerated as an important part of the healthcare providers' responsibilities $(6,7)$. Moreover, the prolongation of the disease will further emphasize the importance of having self-management programs. These programs can help empower patients to take care of themselves, and facilitates communication with healthcare providers to better manage this disease (8). Using a self-management program, PLWH can receive educational information in a variety of areas such as safe sex behaviors and adherence to the medication regimens. Furthermore, through a self-management program, motivation and contribution of PLWH for continuing the disease treatment will be increased (9). Based on similar articles, due to the effect of self-management on improving the treatment process, development of a self-management system of chronic conditions is necessary (10-12). Likewise, expanding mobile application in the healthcare industry has increased the use of this technology to provide selfmanagement services (13-15). A mobile-based self-management system can be used for telecommunication and data gathering from the distance and therefore reduces the cost and saves time $(16,17)$. The first step to develop a mobile-based self-management system is in analyzing literature to identify the technical features and data elements for standard data gathering and practice in an integrated manner (18). Mobile-based self-management systems are an appropriate and socially relevant approach for intervention delivery, as younger adult populations have been identified as having high rates of mobile phone use (19). Technical capabilities such as educational and motivational messages, text message reminders and mobile-based adherence interventions have shown some success in HIV infected people (20). A pilot intervention using a mobile-based self-management system in 14 to 29 year olds demonstrated significant improvements in self-management adherence at the HIV treatment intervention (21). In addition to technical capabilities, standard data elements can also be useful in providing health services to PLWH. Clinical and demographic data gathering using standard data elements will be possible (22). In the other words, data gathering is the main part of information management and the data elements are a standard tool to assure the quick access to accurate and detailed healthcare information (23). With the use of the data elements, standard data, which are required to access innovative and reliable information of patients, diseases, new therapeutic methods, and their outcomes, are gathered from all healthcare providers. Many organizations use data elements to develop documentation standards as well as uniform descriptions for describing what has happened (24-27).

Mobile-based self-management systems with technical features and common data elements for providing, evaluating, and improving HIV care are significantly required in developing countries that are bearing the effect of the HIV epidemic (28). Unfortunately, in spite of the disturbing prevalence and consequences of HIV infection, selfmanagement systems with standard features are just now being deployed in a few developing countries such as subSaharan Africa, where less than $10 \%$ of all PLWH are receiving treatment (29). Similarly, there has been little experience in the gathering and managing of healthcare data in such countries and consequently, few analyzable data from PLWH are used in routine HIV care. As a result, without technical capabilities to self-management adherence at the HIV treatment intervention and standard data elements to collect and access new and credible healthcare data, it is impossible to take an empiric approach to enhance HIV care delivery and the ongoing monitoring and evaluation of HIV services at regional and national levels $(28,30)$. However, in Iran, as a developing country, there has not been a mobile-based self-management system for PLWH with the aforementioned capabilities up to the present time (31). This study was done to determine common elements and features of a mobile-based selfmanagement system for people living with HIV.

\section{Material and Methods}

The present study was a cross-sectional study that determined the common elements and features of designing a mobile-based self-management system for people living with HIV in two phases: 1. Detection of common elements and features, and 2. Selecting data elements and technical capabilities for a mobile-based self-management system. In the first phase, a review study was done with search in databases such as; PubMed, Scopus, Up To Date, and Web of Science. The keywords used to search for resources included; Self-care, Self-management, Data elements, Minimum data set, Mobile application, Mobile health, and HIV/AIDS. The following criteria were considered for selecting the studies related to common elements of mobile-based self-management for PLWH: 1) Type of a study: The research papers and review articles were selected, and newspapers, reports, editorial letters, and abstracts were not examined, 2) Date of publication: The papers published between 2000 and 2017 were reviewed, 3) Language: 
Only papers published in English were examined, 4) Keywords in the title or abstract: As the keywords could be found in different papers as general terms, only full text papers with the keywords in the title or abstracts were selected. Using the search strategies, 111 references were retrieved and 9 papers were thoroughly surveyed (Figure $1)$.

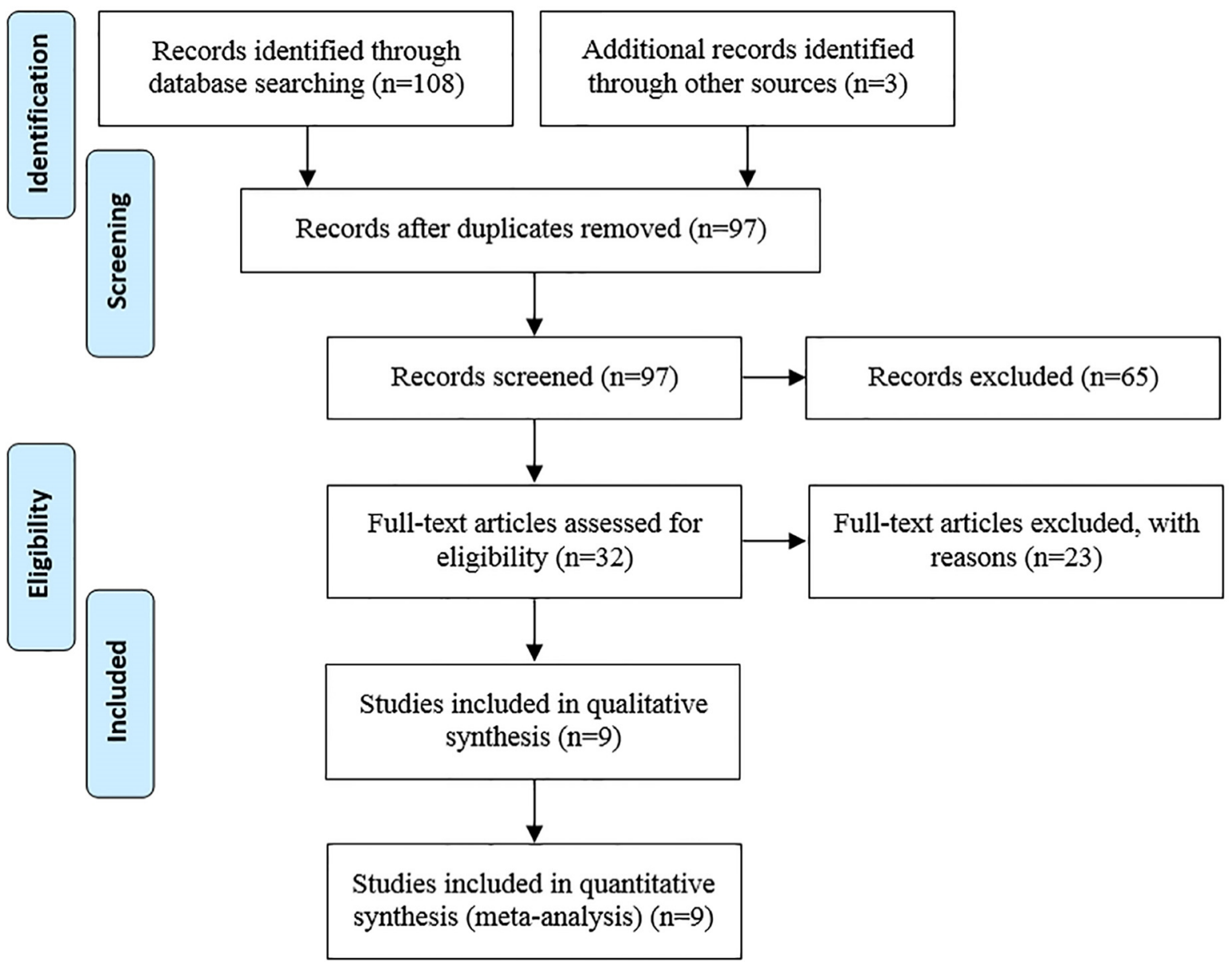

Figure 1. Search results from different databases

By reviewing the identified articles and using the information obtained from the review of similar papers (17, 3239 ), the data elements and technical features were identified and a questionnaire was developed for the need assessment required for designing a mobile-based self-management system for PLWH. The questionnaire consisted of three parts and 37 questions, including clinical data elements (17 questions), demographic data elements (8 questions), and technical capabilities (12 questions), which were based on the 5-point Likert scale (completely agree, agree, no idea, disagree, and completely disagree). The content validity of the questionnaire was measured by four infectious diseases specialists and three experts in health information management. In order to collect data and increase the number of participants in the study, a face-to-face meeting approach was used. To ensure the reliability of the questionnaire, it was completed by seven of the aforementioned specialists and experts; they were requested to complete the questionnaire for the second time after one week. The collected data were analyzed with SPSS 19 and the reliability of the questionnaire was calculated 0.87 by Cronbach's alpha. In the next phase, the infectious diseases specialists and health information management (HIM) professionals were questioned about the clinical, demographic and technical requirements of the system using a researcher-made questionnaire. The statistical population were all infectious diseases specialists working in the AIDS Research Center $(n=15)$ and health information management professionals working at the Faculty of Allied Medical Sciences, Tehran University of Medical Sciences $(n=6)$ in Tehran. The data obtained from the specialists and professionals $(n=21)$ were analyzed using SPSS version 19 (SPSS Inc., Chicago, Illinois, USA), and descriptive statistics (frequency distribution and mean reports). In this way, all of the questionnaires were completed (response rate was 100\%) and the data elements 
and technical capabilities in the questionnaire were scored from 1 to 5 (5 for completely agree, 4 for agree, 3 for having no idea, 2 for disagree, and 1 for completely disagree). Each of the data elements and features that had obtained at least a mean score of 2.5 or more was considered as selected data elements and features.

\section{Results}

We obtained a set of data elements and features of the mobile-based self-management system for PLWH comprised of three categories: clinical data elements, demographic data elements, and technical capabilities. By review of literature, 17 data elements for the clinical category (fever, chills, rash, night sweats, muscle aches, sore throat, fatigue and tiredness, swollen lymph nodes, mouth ulcers, vital signs, associated diseases, current medication, weight loss, diarrhea, pneumonia, neurologic disorders, and skin blotches), 8 data elements for the demographic category (age, gender, marital status, level of education, occupation, weight, height, and BMI), and 12 features for technical capabilities (educational messages, motivational messages, drug taking reminder, appointment reminder, exercise reminder, diet reminder, being user-friendly, security requirements, content of text messages, data collection, internet access, and providing self-management instructions) were identified. In the second phase of this study, the identified data elements and features were scored by 21 samples of attended specialists and experts. According to the findings, 11 data elements were selected by statistical population for the clinical category. In this section, "fever" and "fatigue and tiredness" had the highest and lowest mean (4.9 and 1.8, respectively). Moreover, all of the identified technical requirements were selected by specialists and professionals' "data collection". Finally, among the eight data elements of the demographic category, 6 data elements were selected. In this category, "height" and "BMI" were not selected as required demographic data elements for a mobile-based self-management system for PLWH. The average of given scores and final selected clinical and demographic data elements and technical capabilities are shown in Table 1.

Table 1. The average of given scores and selected data elements and features

\begin{tabular}{|c|c|c|c|c|c|c|c|c|}
\hline \multicolumn{3}{|l|}{ Clinical } & \multicolumn{3}{|l|}{ Technical capabilities } & \multicolumn{3}{|l|}{ Demographic } \\
\hline Data element & Value & SDE & Feature & Value & SF & Data element & Value & SDE \\
\hline Fever & 4.9 & $\sqrt{ }$ & Educational messages & 4.9 & $\sqrt{ }$ & Age & 4.4 & $\sqrt{ }$ \\
\hline Chills & 4.5 & $\sqrt{ }$ & Motivational messages & 4.4 & $\sqrt{ }$ & Gender & 4.6 & $\sqrt{ }$ \\
\hline Skin blotches & 3.3 & $\sqrt{ }$ & Drug taking reminder & 5 & $\sqrt{ }$ & Marital status & 4.5 & $\sqrt{ }$ \\
\hline Rash & 2.3 & & Appointment reminder & 3.9 & $\sqrt{ }$ & Height & 2.3 & \\
\hline Night sweats & 2.9 & $\sqrt{ }$ & Exercise reminder & 4.6 & $\sqrt{ }$ & Occupation & 3.3 & $\sqrt{ }$ \\
\hline Muscle aches & 4.2 & $\sqrt{ }$ & Diet reminder & 4.9 & $\sqrt{ }$ & Weight & 4.2 & $\sqrt{ }$ \\
\hline Sore throat & 2.3 & $\sqrt{ }$ & Being user-friendly & 4.5 & $\sqrt{ }$ & Education level & 2.9 & $\sqrt{ }$ \\
\hline $\begin{array}{l}\text { Fatigue \& } \\
\text { Tiredness }\end{array}$ & 1.8 & & Security requirements & 4.9 & $\sqrt{ }$ & \multirow[t]{10}{*}{$\begin{array}{l}\text { Body Mass Index } \\
\text { (BMI) }\end{array}$} & \multirow[t]{10}{*}{2.4} & \multirow[t]{10}{*}{$\sqrt{ }$} \\
\hline $\begin{array}{l}\text { Swollen lymph } \\
\text { nodes }\end{array}$ & 4.7 & $\sqrt{ }$ & $\begin{array}{l}\text { Content of text } \\
\text { messages }\end{array}$ & 3.3 & $\sqrt{ }$ & & & \\
\hline Mouth ulcers & 2.6 & $\sqrt{ }$ & Data collection & 1.7 & & & & \\
\hline Vital signs & 2.3 & & Internet access & 4.2 & $\sqrt{ }$ & & & \\
\hline Associated diseases & 2 & & \multirow{6}{*}{$\begin{array}{l}\text { Self-management } \\
\text { instructions }\end{array}$} & \multirow[t]{6}{*}{3.3} & \multirow[t]{6}{*}{$\sqrt{ }$} & & & \\
\hline $\begin{array}{l}\text { Neurological } \\
\text { disorders }\end{array}$ & 3 & $\sqrt{ }$ & & & & & & \\
\hline Current medication & 2.3 & & & & & & & \\
\hline Weight loss & 3.3 & $\sqrt{ }$ & & & & & & \\
\hline Diarrhea & 4.1 & $\sqrt{ }$ & & & & & & \\
\hline Pneumonia & 4.6 & $\sqrt{ }$ & & & & & & \\
\hline
\end{tabular}

SDE: selected data elements; SF: selected features

\section{Discussion}

The healthcare providers, while emphasizing on the self-management of HIV/AIDS, state that the best practice in this program is to register patients' information to manage their own conditions as much as possible $(40,41)$. The mobile-based self-management system includes formal features designed to empower PLWH to record their health conditions and collaborate with health care providers. Using a mobile-based self-management system, PLWH can record and share personal and clinical information with healthcare providers and play a pivotal, active, and informed role in managing the physical, psychological and social aspects of the disease $(42,43)$. No special or standard data 
elements and technical features have been developed to register healthcare and individual information of HIV in Iran. It is evident that standardization leads to conceptual interoperability. Therefore, standard definitions should be used for data with minimal free text (44). According to the findings of this paper, 11 data elements were selected for the clinical category of a mobile-based self-management system for people living with HIV. Structured and accessible clinical data set is a prerequisite for optimum information management and efficient clinical procedures in every healthcare organization (45). Due to importance of AIDS and self-management in advancing the therapeutic goals of the disease treatment, the existence of an information system that is focused on providing self-management services can be an important achievement for healthcare organizations (46). PLWH would like to stay anonymous and avoid in-person health visits because of the nature of their disease. Therefore, the existence of a data set that contains clinical information of patients and establishes a distanced communication between patients and healthcare centers as well as providing social and psychological support to these patients $(47,48)$, can be hugely beneficial. According to the findings, technical capabilities of a mobile-based self-management system for PLWH needs to features such as; drug taking reminder, educational messages, security requirements, content of the text messages, self-management instructions, and internet access. One major problem with HIV condition management is ensuring PLWH treatment tracking including prevention/interventions programs, medication, and clinical checkups until finishing point. HIV positive people should be adherent to the medication regimens because the lack of timely administration of drugs leads to more resistance to the virus and therefore, the drugs should be prescribed in higher doses, which would increase the cost and side effects (40). Technical capabilities of a mobile-based selfmanagement system can be very helpful by giving reminders and engaging patients in therapeutic activities (41). A 2016 clinical trial by Garofalo et al., showed that the effect of a text message-based system containing complete clinical information for the continuation of treatment in the subjects was significant after 6 months. Also, the satisfaction of the subjects was very high with the intervention, which indicated the feasibility and initial effectiveness of the intervention. The researchers' suggestion in the study indicated the need for the use of mobilebased software and applications with the information of PLWH (49). Nhavoto et al., in a similar study, designed a web-based system to support tracking the treatment of people with HIV. In their study, system requirements were determined into 6 categories: data collection requirements, telecommunications cost, data confidentiality and security, text message content, communication, and system scalability. The findings of this study showed that the system could improve self-management and self-care skills of patients and strengthen the relationship between patients and health care providers (50). Moreover, we develop a demographic category with 8 data elements including the weight, marital status, gender, age, occupation, and level of education. It is necessary that organized personal information of patients be accessible in every healthcare organization and therefore, the need to develop demographic data elements for managing the individual data is evident (28). Healthcare specialists believe that the use of demographic information such as age and marital status are essential to improve HIV care (51). It is evident that the complete registration of patients' identity information can improve HIV/AIDS healthcare services through identifying their individual and social characteristics and changing the traditional interactions between healthcare providers (52). According to the principles of self-management, all people with HIV/AIDS should record the necessary clinical and personal information in the software. The completeness of the patient's personal information will help to allocate enough time to administer prescribed medications, manage side-effects of treatment, address mental health, and lifestyle issues such as exercise, diet, drugs, and alcohol consumption (53-55).

\section{Conclusions}

In this paper, we determined the common elements and features of a mobile-based self-management system in three different categories: clinical (with 11 data elements), demographic (with 6 data elements) and technical capabilities (with 10 features). Using these requirements, it is possible to structure data gathering, medication adherence, and communication with healthcare providers in a standard manner. It is suggested that appropriate policies and national grants be adopted to identify and prioritize a minimum data set to support the healthcare services of people living with chronic conditions. A complementary study to identify the additional requirements such as technology infrastructures and security requirements of a mobile-based self-management system for PLWH through a semiexperimental methodology can be an appropriate route to future research on this topic.

\section{Acknowledgments:}

This article is the result of the $\mathrm{PhD}$ dissertation on health information management at Tehran University of Medical Sciences. The authors extend thanks to infectious diseases specialists working at the Iranian Research Center for HIV/AIDS (IRCHA) and health information management professionals working at the Faculty of Allied Medical Sciences, Tehran University of Medical Sciences. In addition, we thank all the participants for taking time to participate in the study and Siavash Forootan and Saghar Mirshekari for editorial and technical assistance. 


\section{Conflict of Interest:}

There is no conflict of interest to be declared.

\section{Authors' contributions:}

All authors contributed to this project and article equally. All authors read and approved the final manuscript.

\section{References:}

1) Joint United Nations Programme on HIV/AIDS (UNAIDS) 2010. UNAIDS Report on the global AIDS epidemic 2010. WHO Library Cataloguing-in-Publication Data. Available from: http: www.unaids.org.

2) Kramer A, Kretzschmar M, Krickeberg K. Modern infectious disease epidemiology: Concepts, methods, mathematical models, and public health. Springer Science \& Business Media; 2010.

3) HIV/AIDS fact sheet. World Health Organization. Available from: http://www.who.int/mediacentre/factsheets/fs360/en/. doi: 10.1007/978-0-387-93835-6.

4) About HIV/AIDS. Centers for disease control and prevention. Available from: https://www.cdc.gov/hiv/basics/whatishiv.html.

5) Stewart NM. Self-management programs for people with HIV. HIV Australia, 2010; 8(1): 1-6.

6) Millard T, McDonald K, Elliott J, Slavin S, Rowell S, Girdler S. Informing the development of an online self-management program for men living with HIV: a needs assessment. BMC Public Health. 2014; 14(1209): 1-9. doi: 10.1186/1471-2458-14-1209.

7) Sullivan KM, Inouye J. Feasibility of a Group-Based Self-Management Program for Ethnically Diverse People with HIV/AIDS in Hawaii. Asian / Pacific Island Nursing Journal, 2015; 1(2): 1-11.

8) Igodan CE, Akinyokun OC, Olatubosun O. Online Fuzzy-Logistic Knowledge Warehousing and Mining Model for the Diagnosis and Therapy of HIV/AIDS. International Journal of Computational Science and Information Technology. 2013; 1(3): 27-40. doi: 10.5121/ijcsity.2013.1304.

9) Iribarren S, Siegel K, Hirshfield S, Olender S, Voss J, Krongold J, et al. Self-Management Strategies for Coping with Adverse Symptoms in Persons Living with HIV with HIV Associated Non-AIDS Conditions. AIDS and Behavior. 2017. doi: 10.1007/s10461-017-1786-6.

10) Mohammadzadeh N, Safdari R. Patient monitoring in mobile health: opportunities and challenges. Medical Archives. 2014; 68(1): 57. doi: 10.5455/medarh.2014.68.57-60. PMID: 24783916, PMCID: PMC4272470.

11) Mehraeen E, Ayatollahi H, Ahmadi M. Health Information Security in Hospitals: the Application of Security Safeguards. Acta Inform Med. 2016; 24(1): 47-50. doi: 10.5455/aim.2016.24.47-50. PMID: 27046944, PMCID: PMC4789743.

12) Mohammadzadeh N, Safdari R, Rahimi A. Cancer care management through a mobile phone health approach: key considerations. Asian Pacific Journal of Cancer Prevention. 2013; 14(9): 4961-4. doi: 10.7314/APJCP.2013.14.9.4961. PMID: 24175759.

13) Kirk GD, Himelhoch SS, Westergaard RP, Beckwith CG. Using mobile health technology to improve HIV care for persons living with HIV and substance abuse. AIDS Research and Treatment. 2013; 194613: 1-4. doi: $10.1155 / 2013 / 194613$.

14) Parmanto B, Pramana G, Daihua XY, Fairman AD, Dicianno BE. Development of mHealth system for supporting self-management and remote consultation of skincare. BMC Medical Informatics and Decision Making. 2015; 15(114): 1-8. doi: 10.1186/s12911-015-0237-4.

15) Mavhemwa PM, Muzurura O. Evaluating the effectiveness of m-health based Diabetes Self-Management and community based networking. International Journal of Emerging Trends \& Technology in Computer Science. 2013; 2(4): 166-184.

16) Mbuagbaw L, Mursleen S, Lytvyn L, Smieja M, Dolovich L, Thabane L. Mobile phone text messaging interventions for HIV and other chronic diseases: an overview of systematic reviews and framework for evidence transfer. BMC Health Services Research,.2015; 15(33): 1-16. doi: 10.1186/s12913-014-0654-6.

17) Ramanathan N, Swendeman D, Comulada WS, Estrin D, Rotheram-Borus MJ. Identifying preferences for mobile health applications for self-monitoring and self-management: Focus group findings from HIVpositive persons and young mothers. International journal of medical informatics. 2013; 82(4): e38-46.

18) Abdelhak M, Grostick S, Hanken MA. Health Information: Management of a Strategic Resource. 3rd ed Philadelphia: Elsevier; 2007.

19) Fjeldsoe BS, Marshall AL, Miller YD. Behavior change interventions delivered by mobile telephone shortmessage service. Am J Prev Med. 2009; 36(2): 165-73. doi: 10.1016/j.amepre.2008.09.040. PMID: 19135907. 
20) Cole-Lewis H, Kershaw T. Text messaging as a tool for behavior change in disease prevention and management. Epidemiol Rev. 2010; 32(1): 56-69. doi: 10.1093/epirev/mxq004. PMID: 20354039, PMCID: PMC3082846.

21) Belzer ME, Naar-King S, Olson J, Sarr M, Thornton S, Kahana SY, et al. Adolescent Medicine Trials Network for HIV/AIDS Interventions. The use of cell phone support for non-adherent HIV-infected youth and young adults: an initial randomized and controlled intervention trial. AIDS and Behavior. 2014; 18(4): 686-96. doi: 10.1007/s10461-013-0661-3. PMID: 24271347, PMCID: PMC3962719.

22) Johns ML. Health Information Management Technology: An Applied Approach. Chicago: Am Health Info Manage Assoc; 2002.

23) Hosseini AS, Moghaddasi H, Jahanbakhsh M. designing minimum data sets of diabetes mellitus: basis of effectiveness indicators of diabetes management. Health Info Manage. 2010; 7(3): 330-40.

24) New Zealand Health Information Service. National Minimum Dataset (Hospital Events): NMDS; 2010. Available from: www.moh. govt.nz/moh.nsf/indexmh/dataandstatistics-technicalnmds/.

25) Guidelines for the establishment and management of clinical registries. Australian Commission on Safety and Quality in Health Care. Sydney, Australia; 2009.

26) Tierney WM, Beck EJ, Gardner RM, Musick B, Shields M, Shiyonga NM, et al. Viewpoint: a pragmatic approach to constructing a minimum data set for care of patients with HIV in developing countries. J Am Med Inform Assoc. 2006; 13(3): 253-60. doi: 10.1197/jamia.M2005. PMID: 16501175, PMCID: PMC1513663.

27) Ahmadi M, Mohammadi A, Chraghbaigi R, Fathi T, Baghini MS. Developing a Minimum Data Set of the Information Management System for Orthopedic Injuries in Iran. Iran Red Crescent Med J. 2014; 16(7): e17020.

28) Tierney WM, Beck EJ, Gardner RM, Musick B, Shields M, Shiyonga NM, Spohr MH. a pragmatic approach to constructing a minimum data set for care of patients with HIV in developing countries. Journal of the American Medical Informatics Association. 2006; 13(3): 253-60.

29) Fleishman JA, Yehia BR, Moore RD, Gebo KA, HIV Research Network. The economic burden of late entry into medical care for patients with HIV infection. Medical care. 2010; 48(12): 1071. doi: 10.1097/MLR.0b013e3181f81c4a. PMID: 21063228 , PMCID: PMC3022268.

30) Chen RY, Accortt NA, Westfall AO, Mugavero MJ, Raper JL, Cloud GA, et al. Distribution of health care expenditures for HIV-infected patients. Clinical Infectious Diseases. 2006; 42(7): 1003-10. doi: 10.1086/500453. PMID: 16511767.

31) Nematollahi M, Khalesi N, Moghaddasi H. A Comparative Study of Management Information System for HIV / AIDS in selected countries. Payesh. 2012; 11(4): 425-33.

32) Blackstock OJ, Patel VV, Cunningham CO. Use of technology for HIV prevention among adolescent and adult women in the United States. Curr HIV/AIDS Rep. 2015; 12(4): 489-99. doi: 10.1007/s11904-0150287-3. PMID: 26412086, PMCID: PMC4643397.

33) Thompson MA, Mugavero MJ, Amico KR, Cargill VA, Chang LW, Gross R, et al. Guidelines for improving entry into and retention in care and antiretroviral adherence for persons with HIV: evidencebased recommendations from an International Association of Physicians in AIDS Care panel. Annals of internal medicine. 2012; 156(11): 817-33. doi: 10.7326/0003-4819-156-11-201206050-00419. PMID: 22393036, PMCID: PMC4044043.

34) Fan V, Duran D, Silverman R, Glassman A. HIV/AIDs intervention packages in five countries: a review of budget data. Center for Global Development Policy Paper. 2013; (33).

35) Tierney WM, Beck EJ, Gardner RM, Musick B, Shields M, Shiyonga NM, et al. A pragmatic approach to constructing a minimum data set for care of patients with HIV in developing countries. Journal of the American Medical Informatics Association. 2006; 13(3): 253-60. doi: 10.1197/jamia.M2005. PMID: 16501175, PMCID: PMC1513663.

36) Tierney WM, Rotich JK, Hannan TJ, Siika AM, Biondich PG, Mamlin BW, et al. The AMPATH medical record system: creating, implementing, and sustaining an electronic medical record system to support HIV/AIDS care in western Kenya. Studies in health technology and informatics. 2007; 129(1): 372. PMID: 17911742.

37) McDonald K, Slavin S, Pitts MK, Elliott JH, HealthMap Project Team. Chronic disease self-management by People With HIV. Qualitative health research. 2016; 26(6): 863-70. doi: 10.1177/1049732315600415. PMID: 26290540. 
38) van Olmen J, Schellevis F, Van Damme W, Kegels G, Rasschaert F. Management of chronic diseases in sub-Saharan Africa: cross-fertilisation between HIV/AIDS and diabetes care. Journal of tropical medicine. $2012 ; 2012$.

39) Schnall R, Bakken S, Rojas M, Travers J, Carballo-Dieguez A. mHealth technology as a persuasive tool for treatment, care and management of persons living with HIV. AIDS Behav. 2015; 19(2): 81-9. doi: 10.1007/s10461-014-0984-8. PMID: 25572830, PMCID: PMC4497931.

40) Henry BL, Moore DJ. Preliminary Findings Describing Participant Experience With iSTEP, an mHealth Intervention to Increase Physical Activity and Improve Neurocognitive Function in People Living with HIV. J Assoc Nurses AIDS Care. 2016; 27(4): 495-511. doi: 10.1016/j.jana.2016.01.001. PMID: 26847379 , PMCID: PMC4903897.

41) Niakan S, Mehraeen E, Noori T, Gozali E. Web and Mobile Based HIV Prevention and Intervention Programs Pros and Cons - A Review. Studies in Health Technology and Informmatics. 2017; 236: 319-27. PMID: 28508813.

42) Stoller EP, Webster NJ, Blixen CE, McCormick RA, Perzynski AT, Kanuch SW, et al. Lay management of chronic disease: a qualitative study of living with hepatitis C infection. Am J Health Behav. 2009; 33(4): 376-90. doi: 10.5993/AJHB.33.4.4. PMID: 19182983, PMCID: PMC2720158.

43) Phillips KA, Epstein DH, Mezghanni M, Vahabzadeh M, Reamer D, Agage D, et al. Smartphone delivery of mobile HIV risk reduction education. AIDS Res Treat. 2013; 2013: 231956. doi: 10.1155/2013/231956. PMID: 24159383, PMCID: PMC3789326.

44) Tierney WM, Beck EJ, Gardner RM, Musick B, Shields M, Shiyonga NM, et al. Viewpoint: a pragmatic approach to constructing a minimum data set for care of patients with HIV in developing countries. J Am Med Inform Assoc. 2006; 13(3): 253-60. doi: 10.1197/jamia.M2005. PMID: 16501175, PMCID: PMC1513663.

45) Pakgaohar A, Sadegi Kia A. Analysis of accident data by decision trees. Traffic Manage Study. 2009; 3(8): $27-47$.

46) Lorig KR, Sobel DS, Ritter PL, Laurent D, Hobbs M. Effect of a Self-management Program on Patients with Chronic Disease. Effective Clinical Practice. 2001; 4(6): 256-62. PMID: 11769298.

47) Donovan JL, Blake DR. Qualitative study of interpretation of reassurance among patients attending rheumatology clinics: "just a touch of arthritis, doctor?" BMJ . 2000; 320: 541-4. doi: 10.1136/bmj.320.7234.541. PMID: 10688559, PMCID: PMC27296.

48) Arie S. Can mobile phones transform healthcare in low and middle income countries? BMJ. 2015; 350: h1975. doi: 10.1136/bmj.h1975. PMID: 25902967.

49) Garofalo R, Kuhns LM, Hotton A, Johnson A, Muldoon A, Rice D. A randomized controlled trial of personalized text message reminders to promote medication adherence among HIV-positive adolescents and young adults. AIDS and Behavior. 2016; 20(5): 1049-59. doi: 10.1007/s10461-015-1192-x. PMID: 26362167, PMCID: PMC4788595.

50) Nhavoto JA, Gronlund A, Chaquilla WP. SMSaude: Design, Development, and Implementation of a Remote/Mobile Patient Management System to Improve Retention in Care for HIV/AIDS and Tuberculosis Patients. JMIR Mhealth Uhealth. 2015; 3(1): e26. doi: 10.2196/mhealth.3854. PMID: 25757551, PMCID: PMC437612.

51) Lai TY, Larson EL, Rockoff ML, Bakken S. User acceptance of HIV TIDES--Tailored Interventions for Management of Depressive Symptoms in persons living with HIV/AIDS. J Am Med Inform Assoc. 2008; 15(2): 217-26. doi: 10.1197/jamia.M2481. PMID: 18096915, PMCID: PMC2274800.

52) Tamblyn R, Huang A, Kawasumi Y, Bartlett G, Grad R, Jacques A, et al. The development and evaluation of an integrated electronic prescribing and drug management system for primary care. J Am Med Informatic. 2006; 13 (2): 148-59. doi: 10.1197/jamia.M1887. PMID: 16357357, PMCID: PMC1447542.

53) Miller CW, Himelhoch S. Acceptability of mobile phone technology for medication adherence interventions among HIV-positive patients at an urban clinic. AIDS research and treatment. 2013. doi: $10.1155 / 2013 / 670525$.

54) Belzer ME, Naar-King S, Olson J, Sarr M, Thornton S, Kahana SY, et al. The use of cell phone support for non-adherent HIV-infected youth and young adults: an initial randomized and controlled intervention trial. AIDS and behavior. 2014; 18(4): 686-96. doi: 10.1007/s10461-013-0661-3. PMID: 24271347, PMCID: PMC3962719.

55) L'Engle KL, Green K, Succop SM, Laar A, Wambugu S. Scaled-Up Mobile Phone Intervention for HIV Care and Treatment: Protocol for a Facility Randomized Controlled Trial. JMIR research protocols. 2015; 4(1): e11. 